\title{
Investigation of resonance phenomena in power lines supplying powerful rectifier plants
}

\author{
Svetlana Molot ${ }^{1, *}$, Vasilina Kovalenko ${ }^{1}$, Elena Pylskaya $^{1}$, Ivan Artyukhov ${ }^{1}$, and Sergey Stepanov ${ }^{1}$ \\ ${ }^{1}$ Yuri Gagarin State Technical University of Saratov, Russia
}

\begin{abstract}
A feature of modern power supply systems is the presence of a large number of electrical devises that consume non-sinusoidal current. The examples of the devices are frequency converters or rectifiers of large unit power. But substations for supplying a group of variable frequency drives affect negatively also. Since the equivalent circuit of the power includes line inductive and capacitive elements, under certain conditions, resonant can occur in the power supply system. The model for studying a power supply system with a powerful rectifier load has been developed in the MATLAB + Simulink environment. The equivalent power line circuit is adopted in the form of a certain number of series-connected sections. The number of sections was chosen from the condition of obtaining information about all harmonics, which the electric power quality standard prescribes to analyze. The simulation results show the number of the harmonic at which the resonance occurs depends on the length of the power line. It has been found that at resonance, the maximum current harmonic circulates through the source. And at the end of the line in this moment, the current harmonic has a minimum value, while the corresponding voltage harmonic rises sharply.
\end{abstract}

\section{Introduction}

The intensive introduction of converting devices in various industries is accompanied by the problem of their negative impact on electrical networks. The reason for this phenomenon is that rectifiers, frequency converters, thyristor controllers and other devices using power semiconductor switches consume non-sinusoidal currents. [1]. The spectrum of these currents contains harmonic components, which, passing through power lines, transformers and other elements of the power supply system, distort the voltage shape, create additional power losses, and also the components are a source of interferences [2-4].

In the power supply system under certain conditions resonant modes are able to arise at the frequencies of different harmonics, the danger of the modes is the occurrence of sharp current surges and overvoltages [25]. Therefore, the study of such modes is an urgent task; the solution is being addressed by researchers from different countries [5-8].

\section{Object of Investigation}

The unified energy system of the country provides enterprises and all consumers with standard electricity in the form of three-phase current with a frequency of 50 $\mathrm{Hz}$ and standard voltages from 0.4 to $500 \mathrm{kV}$. But various industries require electricity of different types and parameters. DC systems are widely used in a number of industries, for example for rolling mills. Another large area of DC energy use is electrical technology, where electrolysis plants are used to produce non-ferrous metals. In these industries, to obtain high-power direct current, power rectifiers based on semiconductor elements are used.

Rectifiers are also an input link in the circuits of frequency converters made with an intermediate DC link. The rectifiers in these converters can be made both controlled and uncontrolled, high-voltage and lowvoltage, with or without a matching transformer at the input.

Fig. 1 shows a functional diagram of a variable frequency drive, which has found application at powers from 320 to $1600 \mathrm{~kW}$. The frequency converter, which includes a rectifier, a smoothing filter and an inverter, is designed for a voltage that is lower than the network and motor voltage.

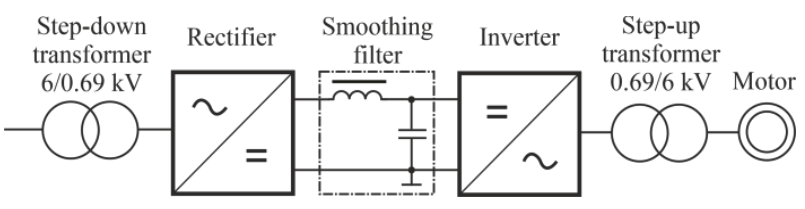

Fig. 1. Functional diagram of a variable frequency drive with a low-voltage frequency conversion link.

Another example of a powerful rectifier load would be an electric power plant to a large group of variable frequency drives. Gas cooling plants are using at compressor stations to ensure the required temperature regime of gas transport (Fig. 2). They represent a set of

\footnotetext{
* Corresponding author: sve_1992@mail.ru
} 
heat exchange sections with electric driven fans, the number of which can be 24 or more units [9]. The total power of variable frequency drives of only one installation is about $1 \mathrm{MW}$.

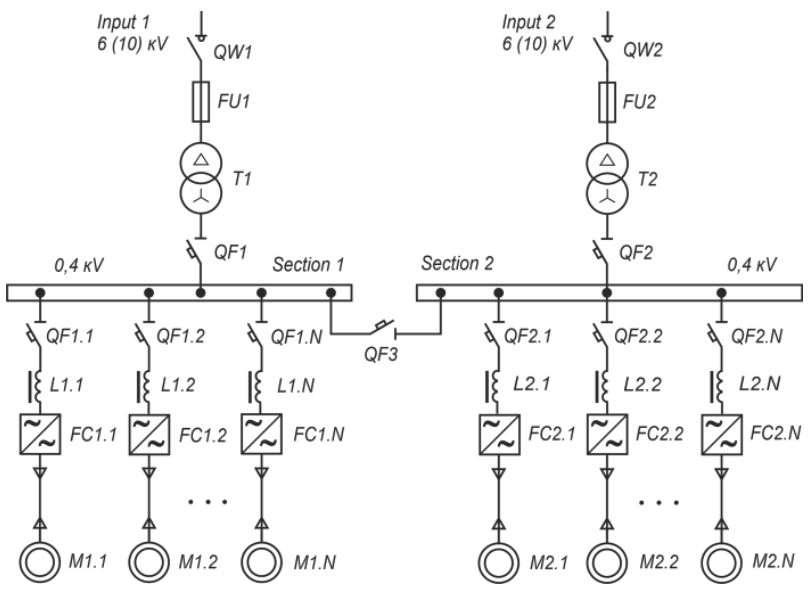

Fig. 2. Variable frequency drive of fans for gas cooling plant.

One of the disadvantages of using power semiconductor technology is the appearance of current and voltage harmonics both on the load side and on the supply network side. The magnitude and composition of these harmonics from the network side depend on the rectifier circuit, the presence of special filters and other factors. Fig. 3 shows circuit that was used for studying the influence of the supply line parameters to the electric power quality in a power supply system with a rectifier load.

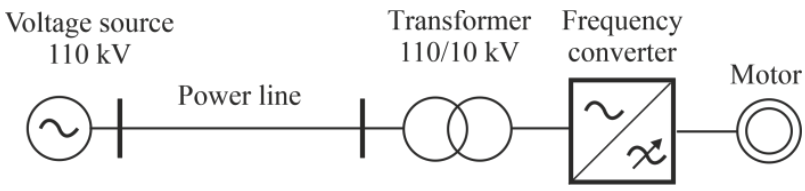

Fig. 3. Single-line diagram of the investigated power supply system.

It is assumed that some frequency converter for motor control is connected to a $110 \mathrm{kV}$ power line via a step-down transformer.

\section{Power supply system modeling}

Accurate calculation of power lines distributed resistances and conductivities is difficult and it is necessary only when the lines length is long. In the calculations, simplified equivalent circuits of the power lines are usually used, in the circuits distributed line parameters are replaced with lumped active and reactive resistances and conductivities [10].

Simplified U-shaped equivalent circuit of transmission line is shown in Fig. 4. This circuit is usually used for calculating $110-220 \mathrm{kV}$ overhead power lines up to $300-400 \mathrm{~km}$ in length. The equivalent circuit consists of series-connected resistance $\left(R_{\mathrm{L}}\right)$ and reactance $\left(X_{\mathrm{L}}\right)$. Active $\left(G_{\mathrm{L}}\right)$ and capacitive $\left(B_{\mathrm{L}}\right)$ conductance is included at the beginning and end of the line by $1 / 2$.

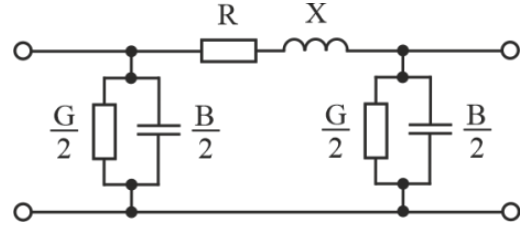

Fig. 4. Simplified U-shaped equivalent circuit of power line.

The equivalent circuit consists of series-connected resistance $\left(R_{\mathrm{L}}\right)$ and reactance $\left(X_{\mathrm{L}}\right)$. Active $\left(G_{\mathrm{L}}\right)$ and capacitive $\left(B_{\mathrm{L}}\right)$ conductance is included at the beginning and end of the line by $1 / 2$.

Line resistance is defined as:

$$
R_{\mathrm{L}}=R_{0} \cdot l
$$

where $R_{0}$ - resistivity at a wire temperature of $+20^{\circ} \mathrm{C}$ $(\Omega / \mathrm{km}), l$ - line length $(\mathrm{km})$.

At a frequency of $50 \mathrm{~Hz}$, the resistance of wires and cables is usually taken equal to the ohmic resistance. The surface effect is neglected. If the wire temperature is other than $+20^{\circ} \mathrm{C}$, the line resistance is determined through the appropriate formulas.

Reactance (inductive reactance) is calculated by the equation:

$$
X_{L}=X_{0} \cdot l
$$

where $X_{0}$ - inductive reactance per unit length $(\Omega / \mathrm{km})$. The inductive reactances per unit length for overhaed power line phases are different. The inductive reactances per unit length for overhead power line phases are different in general. But since the wires are transposed on the line, the average values of the inductive reactances are the same for different phases

The simplified power line circuit has a limited range of applications. It does not allow simulating the processes leading to resonance phenomena at harmonics generated by rectifiers into the network. Therefore, to solve the problem, an equivalent power line circuit is adopted in the form of a certain number of seriesconnected sections (Fig. 5).

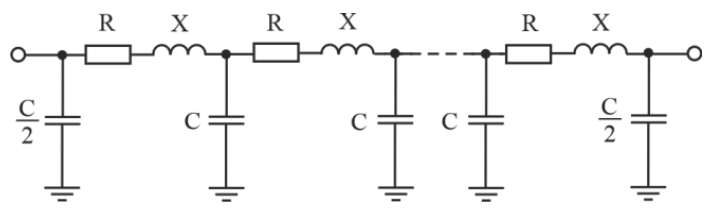

Fig. 5. Equivalent power line circuit in the form of seriesconnected sections.

The number of sections to be used depends on the frequency range to be represented. For a transmission line, the resistance, inductance, and capacitance are uniformly distributed along the line. An approximation of the maximum frequency range represented by the PI line model is given by the following equation:

$$
f_{\max }=\frac{N}{8 \cdot l \cdot \sqrt{L C}},
$$




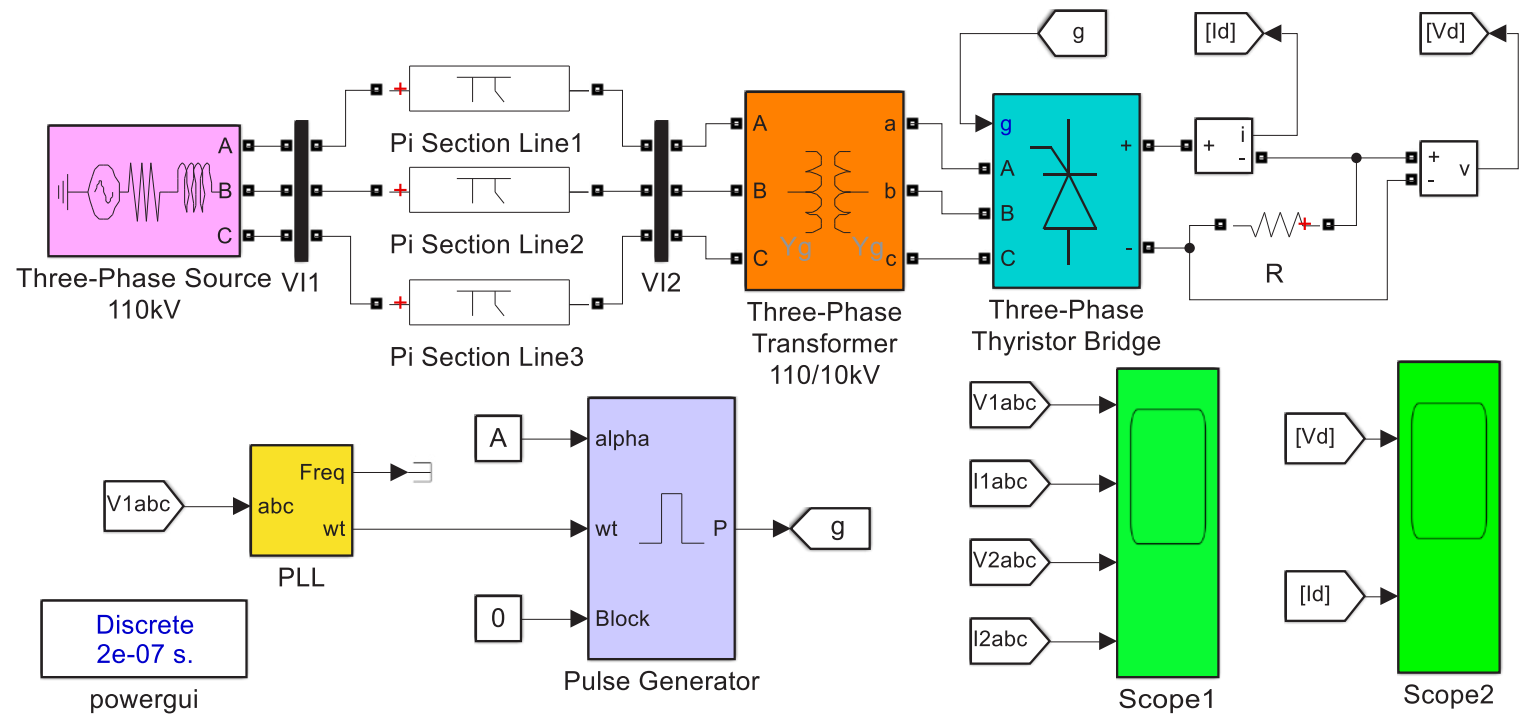

Fig. 6. A simulation model of a power supply system with a rectifier load.

where $N$ - number of PI sections: $l$ - line length $(\mathrm{km}) ; \mathrm{L}-$ inductance $(\mathrm{H} / \mathrm{km}) ; \mathrm{C}$ - capacitance $(\mathrm{F} / \mathrm{km})$.

For example, for a $100 \mathrm{~km}$ overhead line with a propagation speed of $300,000 \mathrm{~km} / \mathrm{s}$, the maximum frequency range represented by one PI segment is approximately $375 \mathrm{~Hz}$. This simple model is sufficient to study the interactions between the power system and the control system. However, for studying of switching overvoltages involving high frequency transients in the range of several $\mathrm{kHz}$, much shorter PI sections should be used.

We are interested in a frequency range of up to 2000 $\mathrm{Hz}$, which allows us to investigate harmonics from 1 to 33 in a $110 \mathrm{kV}$ power line feeding a frequency converter with an input transformer. Therefore, in modeling the line was adopted as an equivalent circuit, consisting of ten series-connected sections.

A simulation model was developed for studying resonance phenomena in a power supply system with a rectifier load; the model scheme is shown in Fig. 6.

The model power part consists of the blocks as Three-Phase Source 110 kV, Pi Section Line, ThreePhase Transformer 110/10 kV and Three-Phase Thyristor Bridge with the load R. Three-Phase VI Measurement blocks are used to obtain information about voltages and currents at the beginning and at the end of a power line.

The vector formation of six double control pulses for the rectifier thyristors is carried out by the Pulse Generator block. The value of the control angle is set at the "alpha" input of this block. The "wt" input is supplied with a synchronization signal from the PLL, which is connected to the VI1 Measurement.

Harmonic analysis of voltages and currents is carried out using the built-in FFT Analysis tool, which uses Fast Fourier Transform technology.

\section{Results}

The simulation results are the non-sinusoidality indexes of voltages and currents depending on power line length. The indexes were obtained for the beginning and end of the power line.

On the power supply source, the harmonic voltage components are of low intensity. They are significantly lower than the permissible values specified by the standard for the electric power quality [11], voltage THD does not exceed 0.2. However, at the end of the power line on the primary side of the $110 / 10 \mathrm{kV}$ transformer, a sharp increase in voltage harmonics can be observed. In this case, the length of the line has a significant effect on the value of harmonics.

Fig. 7 shows graphs of THD voltage variation on the high side of the transformer. The graphs of the change in the voltage harmonic indexes with numbers $5,7,11,13$, 17 and 19 on the primary winding of the transformer are shown in Fig. 8 - 10.

With a line length of $200 \mathrm{~km}$, there is a sharp increase in the voltage THD. The 5th harmonic makes the main contribution to the voltage distortion at this line length, the 5th harmonic index reaches $32 \%$ due to resonance. With a line length of $150 \mathrm{~km}$, resonance appears at the 7 th harmonic. The harmonic index reaches $11 \%$. For the 11 th harmonic, there are two resonances: with a line length of $100 \mathrm{~km}$ and $450 \mathrm{~km}$ with index values of $9.3 \%$ and $11.2 \%$, respectively. The last significant 17 th harmonic with a index value of $6 \%$ has a resonance at a line length of $400 \mathrm{~km}$. The values of all listed harmonics exceed the values established by the electric power quality standard.

Resonant phenomena in the studied power supply system have an interesting feature. When resonating to any of the harmonics, an increase in the voltage index of this harmonic occurs at the end of the line, and an 
increase in the current index is observed at the power supply source.

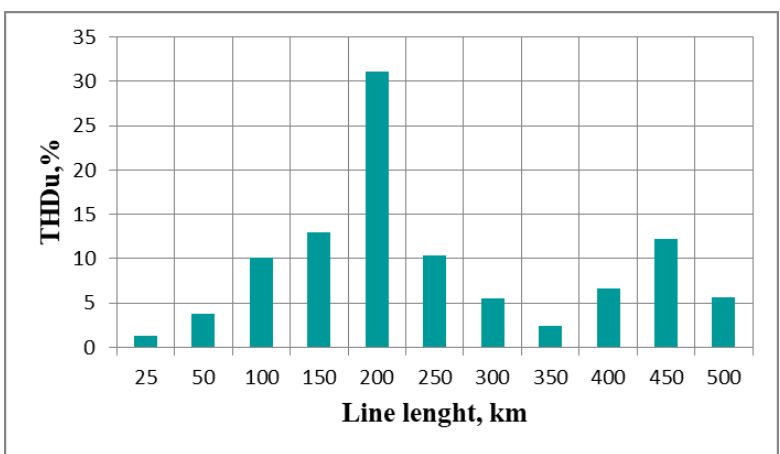

Fig. 7. Voltage THD on the high side of the transformer.

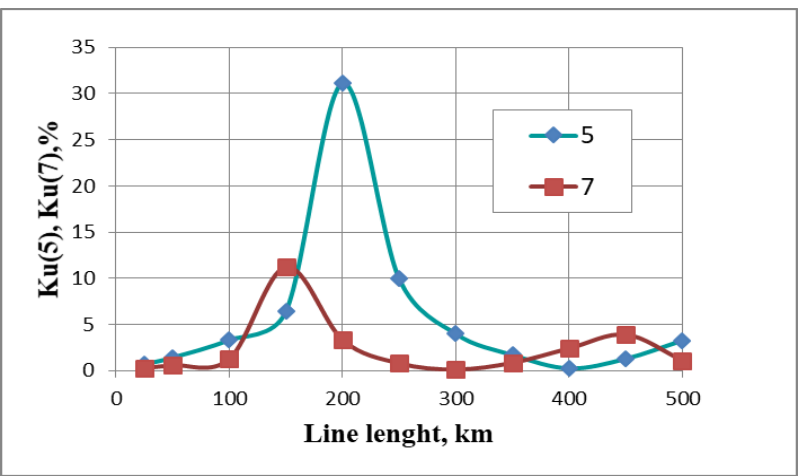

Fig. 8. Index values of the $5^{\text {th }}$ and $7^{\text {th }}$ voltage harmonic on the high side of the transformer.

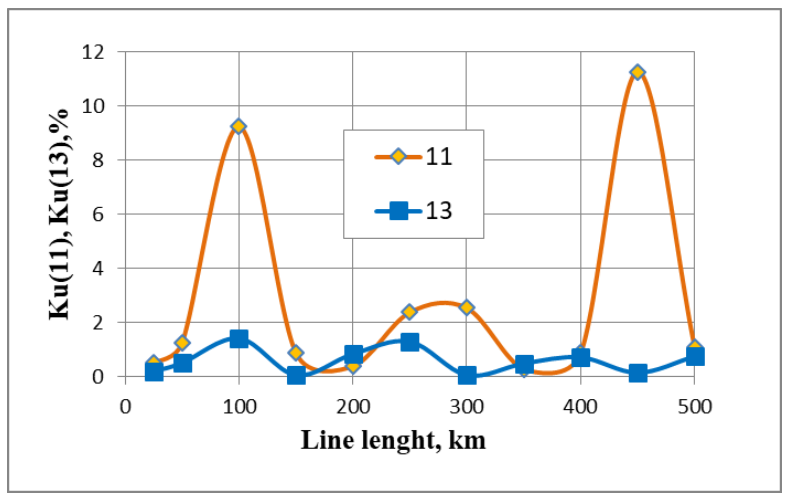

Fig. 9. Index values of the $11^{\text {th }}$ and $13^{\text {th }}$ voltage harmonic on the high side of the transformer.

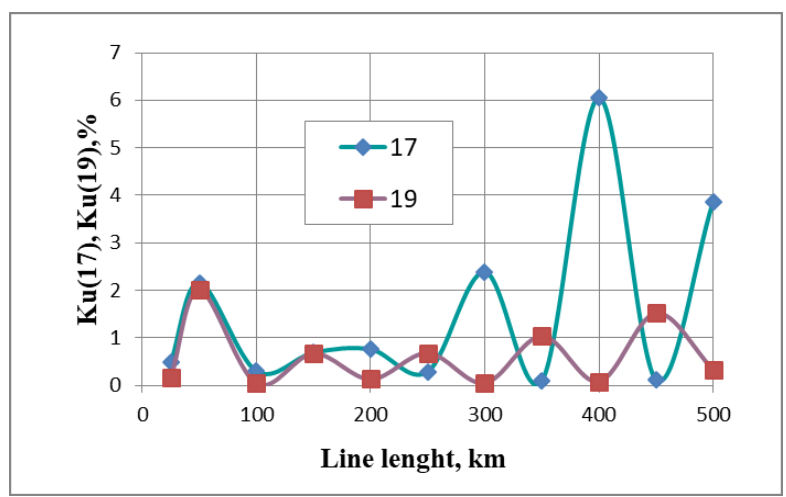

Fig. 10. Index values of the $17^{\text {th }}$ and $19^{\text {th }}$ voltage harmonic on the high side of the transformer.

Fig. 11 shows the graphs of the change in current THD of the source and the primary winding of the $110 / 10 \mathrm{kV}$ transformer. The graphs of the change in the harmonic indexes of these currents with harmonic numbers 5, 7, 11 and 13 are shown in Fig. 12 - 15. The THD of the transformer primary winding current does not exceed $40 \%$ for different line lengths. The current THD of the power supply source exceeds $120 \%$ when resonance is at the 5 th harmonic and reaches $70 \%$ when resonance is at the 7 th harmonic. With a line length of about $100 \mathrm{~km}$, a significant increase in the source current is observed at the 11th and 13th harmonics.

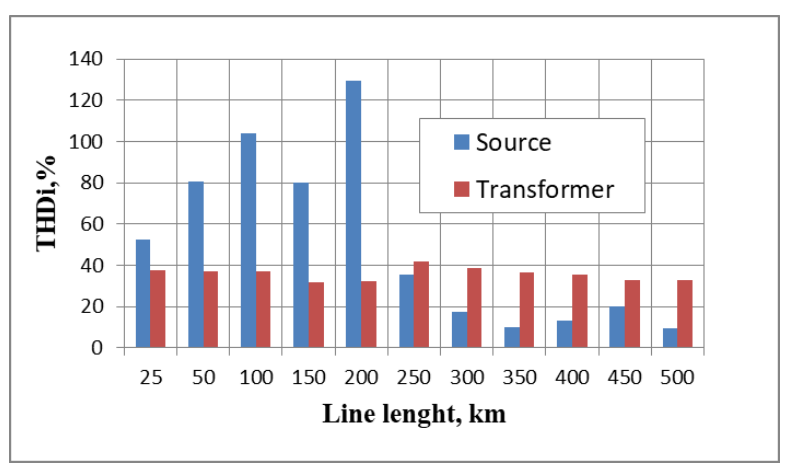

Fig. 11. Current THD of the source and the primary winding of the transformer.

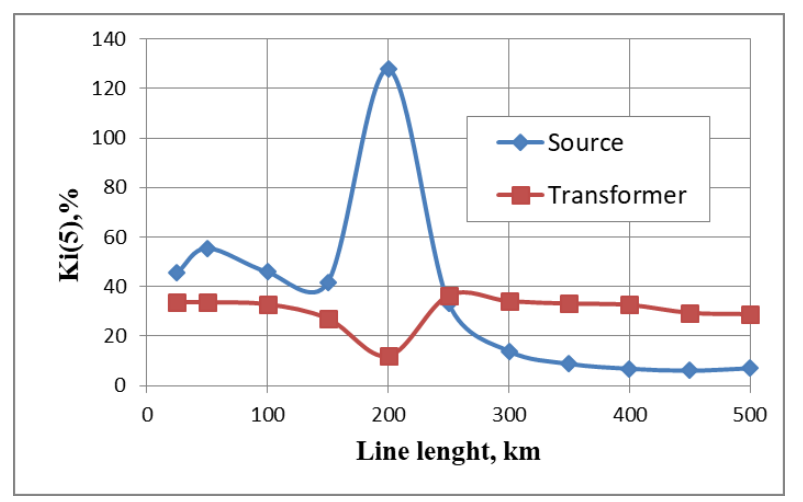

Fig. 12. Index values of the 5 th current harmonic. 


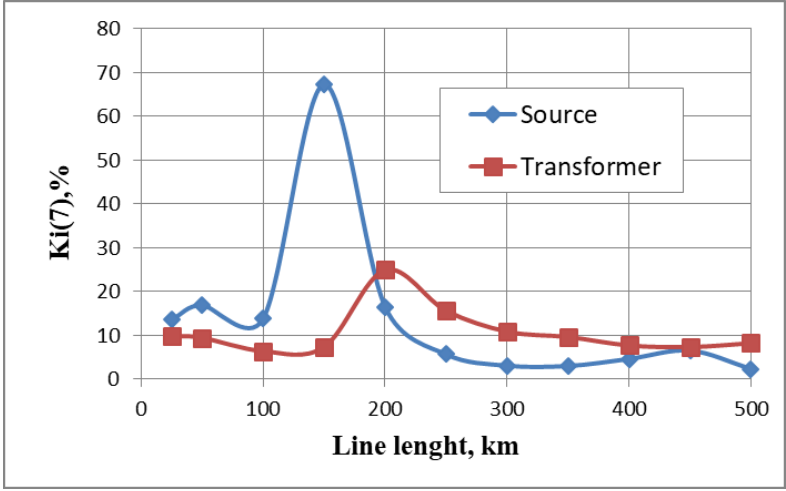

Fig. 13. Index values of the 7th current harmonic.

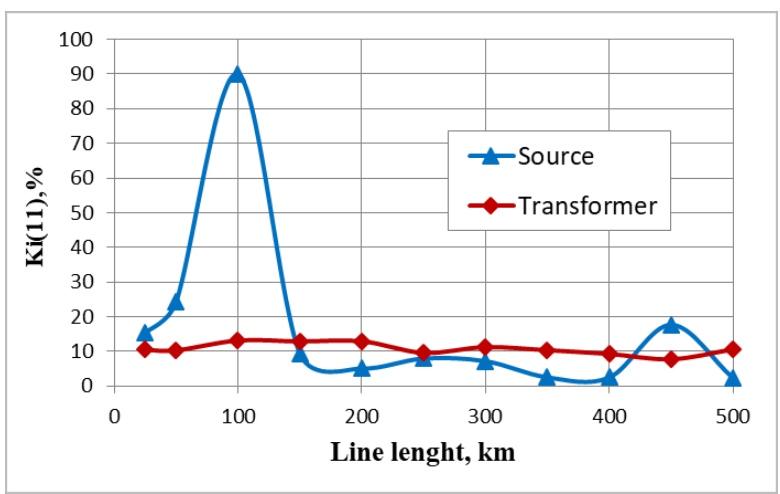

Fig. 14. Index values of the 11 th current harmonic.

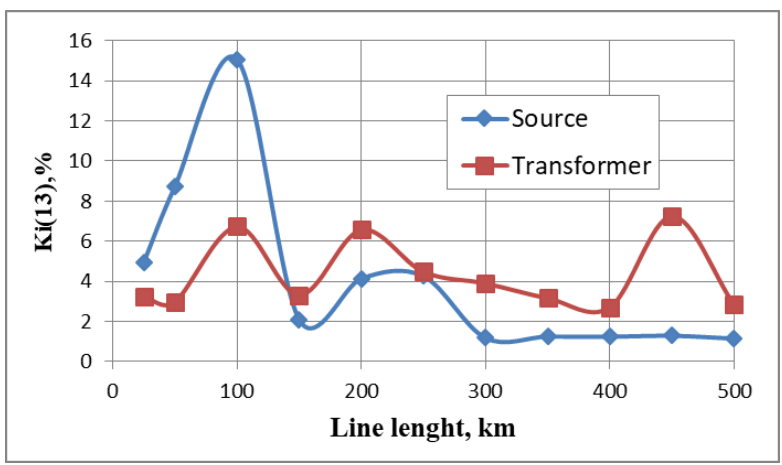

Fig. 15. Index values of the 13 th current harmonic.

The current electric power quality standard does not normalize the values of current harmonic indexes. However, it must be taken into account that the flow of current harmonics in the source and the power line negatively affects the reliability of the power supply system. It should be noted that modern powerful converters are created according to such schemes, in which the emission into the network of the 5th and 7th current harmonics, and in some cases also the 11th and 13th harmonics, is minimized. However, the simulation results show that under certain conditions, a resonance at the 17th harmonic may occur in the power supply system; and the resonance is able to result in a significant excess of this harmonic index on the primary winding of the transformer.

\section{Conclusions}

The model for studying a power supply system with a powerful rectifier load has been developed in the MATLAB + Simulink environment. The simulation results show that resonance phenomena occur in this system. It has been found that the number of the harmonic at which the resonance occurs depends on the length of the power line. In this case, the current and voltage harmonic indexes have different values at the beginning and end of the line. At resonance, the maximum current harmonic circulates through the source. And at the end of the line in this moment, the harmonic current has a minimum value, while the corresponding voltage harmonic rises sharply.

\section{References}

1. G.J. Wakileh, Power system harmonics: fundamentals, analysis and filter design (Springer, New York, 2001)

2. A.Y. Shklyarskiy, S.V. Solovev, Influence of the energy characteristics on the electrical grid simulation, Proceedings of 2015 International Conference on Mechanical Engineering, Automation and Control Systems, MEACS, Tomsk (2015) DOI: 10.1109/MEACS.2015.7414917

3. Y.A. Sychev, Active compensation of voltage dips, deviations and distortions in electrical networks with highly variable loads and long lines, 2016 Electric Power Quality and Supply Reliability (PQ), Tallinn, 41-44 (2016) DOI: 10.1109/PQ.2016.7724087

4. I. Artyukhov, I. Bochkareva, S. Molot, S. Kalganova, S. Stepanov, S. Trigorly, Power quality in industrial isolated generation power systems with powerful nonlinear consumers, Proceedings of $9^{\text {th }}$ International Scientific Symposium on Electrical Power Engineering, Slovakia, 44-49 (2017)

5. T. Vinnal, T. Sakkos, K. Janson, M. Jarkovoi, Resonances in LV industrial networks when using shunt capacitors for power factor correction, Proceedings of 23th International Conference on Electricity Distribution - CIRED 2015, Lyon (1518 June 2015)

6. J. Meyer, R. Stiegler, P. Schegner, I. Röder, A. Belger, Harmoic resonances in residential low voltage networks caused by consumer electronics, Proceedings of 24th International Conference on Electricity Distribution - CIRED 2017, Glasgow (12-15 June 2017)

7. G. Levačić, I. Ivanković, M. Čurin, Mathematical model of power transmission network for calculations in frequency domain, Proceedings of 2nd International Colloquium on Smart Grid Metrology (SMAGRIMET), Split, Croatia (2019) 
8. L.I. Kovernikova, E3S Web of Conferences, 209, 07006 (2020)

9. I.I. Artyukhov, I.I. Arshakyan, A.A. Trimbach, Analysis of circuits of frequency control of gas cooling device's fans, Proceedings of International Conference on Actual Problems of Electron Devices Engineering, 381-389 (2008) DOI: 10.1109/APEDE.2014.6958207

10. H. Dommel, Digital Computer Solution of Electromagnetic Transients in Single and Multiple Networks, IEEE Transactions on Power Apparatus and Systems, PAS-88 (4), 388-396 (1969)

11. State Standard 32144-2013, Electric energy, Electromagnetic compatibility of technical equipment, Power quality requirements in public electricity supply systems, Moscow, Standartinform (2014) 